\title{
BUROCRACIA, DESAFIOS ADMINISTRATIVOS E CIDADES NO BRASIL
}

\section{BUREAUCRACY, ADMINISTRATIVE CHALLENGES AND CITIES IN BRAZIL}

\author{
Glaucia Maria de Araújo Ribeiro ${ }^{1}$ \\ Felipe Asensi ${ }^{2}$
}

\section{Resumo}

O conceito weberiano de burocracia atrelou a característica da previsibilidade à atuação da Administração Pública. Está o agente público, leis e regulamentos, fixando competências funcionais, concentrando meios legais de coerção, surgindo o poder burocrático, cuja atuação impõe o cumprimento regular dos deveres. Este exercício busca contratar pessoas com qualificação técnica para desenvolver a máquina administrativa dentro de uma perspectiva hierárquica de poder estatal. Essa regulamentação específica da Administração Pública teve por efeito prático a separação entre o "público" e "privado", em virtude de uma finalidade impessoal, objetiva, alavancada pela qualificação técnica do agente público e o funcionamento preciso do mecanismo burocrático. A análise deste artigo desenvolve-se ao longo da formação histórica brasileira ao utilizar o método histórico-institucional. Também contextualiza o momento histórico colonial quanto à terminologia "burocracia", período esse de importância máxima para se entender as raízes culturais e sociais do emprego da referida expressão na organização administrativa da cidade brasileira. Com isso, serão apresentados os diversos desafios burocráticos do planejamento das cidades no Brasil, com foco especial no caos urbano.

Palavras-chaves: Cidades, Burocracia, Políticas públicas de planejamento, Caos urbano, Patrimonialismo

\begin{abstract}
The weberian concept of bureaucracy is related to the predictability of the public administration performance. There is the public official, laws and regulations, establishing functional competencies, focusing legal means of coercion, emerging bureaucratic power, whose performance requires the proper performance of the duties. This exercise aims to hire people with technical expertise to develop the administrative machinery within a hierarchical perspective of state power. This specific regulation from the Public Administration had the practical effect of the separation between "public" and "private" because of an impersonal purpose, objective, leveraged the technical qualification of the public official and the precise operation of the bureaucratic mechanism. The analysis of this paper focuses on Brazilian historical formation by using the historical-institutional method. It also contextualizes the colonial historic moment as the term "bureaucracy", a period of high importance to understand the cultural and social roots of the use of those terms to the administrative organization of the Brazilian city. As a result, there will be presented bureaucratic challenges for city planning in Brazil, with special focus on urban chaos.
\end{abstract}

Keywords: Cities, Bureaucracy, Planning of public policies, Urban chaos, Patrimonialism

\footnotetext{
${ }^{1}$ Professora Assistente "C" de Direito Administrativo da Universidade do Estado do Amazonas. Doutoranda em Saúde Coletiva na Área de Concentração "Política, Planejamento e Administração em Saúde". Pesquisadora do Projeto DCR/FAPEAM/CNPQ. E-mail: glauciamariaribeiro@gmail.com

2 Professor Adjunto da Universidade do Estado do Rio de Janeiro (UERJ), Universidade Santa Úrsula (USU) e Universidade Católica de Petrópolis (UCP). Pós-Doutor em Direito pela Universidade do Estado do Rio de Janeiro (UERJ).E-mail: felipedml@yahoo.com.br
} 


\section{INTRODUÇÃO}

O desenvolvimento do modelo e das práticas da burocracia tem desafiado as relações sociais e jurídicas desenvolvidas nas cidades brasileiras, especialmente no que concerne à modernização da administração pública. De fato, observam-se vários fatores de ordem política e jurídica que podem impulsionar a adoção de práticas burocráticas na administração pública. Estes fatores podem apontar, em alguma medida, para a construção de um maior dinamismo à prestação de serviços públicos, apesar de não estarem livres de contradições e desafios.

Os avanços jurídico-institucionais que ocorreram no Brasil - principalmente a partir do processo de redemocratização no final do século XX - traduzem a discussão, de um lado, sobre a formação sociológica e jurídica de nossa administração pública e, de outro, sobre os desafios contemporâneos da relação entre direitos e cidadania. Em termos de direito à cidade, isto ganha especial relevo para a relação entre os cidadãos e os municípios do país.

Este artigo busca refletir sobre a configuração histórica da burocracia na atividade administrativa urbana desde o Brasil colônia até os desafios das cidades no início do século XXI. Neste sentido, a partir do método histórico-institucional, busca-se analisar o desenvolvimento da burocracia no Brasil, de modo a contrastar com a perspectiva teórica de Max Weber sobre a ideia de burocracia na Europa e, especialmente, na Alemanha. Neste sentido, busca-se compreender a extensão da ideia de burocracia para compreender o direito à cidade no Brasil, com foco no planejamento urbano e nas políticas públicas.

Indo além, este artigo analisa a conexão entre a ideia de administração patrimonialista e os atores sociais e políticos inseridos neste contexto, assim como os efeitos desta relação na construção institucional da burocracia no Brasil, especialmente no que concerne aos seguintes aspectos: profusão de legislações, serviços públicos, concentração de poderes e decisões, servidores públicos especializados, irreversibilidade de sistema previdenciário, modelo estatal de regulação, controle administrativo, compras e contratações sob a égide da supremacia do interesse público e as políticas públicas dinâmicas de moradia, saúde e educação. Estes elementos estão fortemente relacionados às tensões enfrentadas no âmbito das cidades, tais como a desburocratização, a introdução do planejamento urbano e, até mesmo, as parcerias entre o público e o privado.

No próximo capítulo, serão analisadas as raízes culturais e sociais da expressão "burocracia", com foco teórico e histórico a respeito da construção da administração pública no 
Brasil e o contraste com a teoria weberiana. Em seguida, serão analisados os limites e desafios da utilização do termo "burocracia" para se discutir o desenvolvimento das cidades e da própria gestão urbana à luz do planejamento das cidades e do caos urbano. Por fim, a título de considerações finais, serão analisados os principais caminhos e impasses para se pensar a articulação entre burocracia e cidades no Brasil.

\section{RAÍZES CULTURAIS E SOCIAIS DA "BUROCRACIA"}

\section{Burocracia e Weber}

A expansão agrícola na Europa resultou em crescimento econômico, especializações de funções, conquistas territoriais, etc. Estes fatores, a partir do século XIII, foram delineando o surgimento do Estado como uma organização política centralizada e burocrática, cuja figura dominante - o soberano - não se confundiu com as demais classes sociais. Este processo social e político ultrapassou séculos, alcançando seu ápice entre os anos de 1450 e 1550.

No século XVIII, os idealizadores ilustrados - tais como Montesquieu, Voltaire, Diderot, Rousseau - trouxeram à tona o princípio fundamental dos Governos: o bem-estar da pessoa humana. Conforme salienta O’Donnel, "a missão da lei é a de determinar e proteger a potestas dos indivíduos, ou seja, sua capacidade de fazer valer sua vontade em todas as esferas não proibidas por essa mesma lei" (O'DONNELL, 1999, p. 605). O lema liberal do "mercado define suas regras" impulsionou os movimentos sociais históricos de reivindicação de direitos, tais como a Revolução Francesa.

No século XIX, Max Weber fez uma importante análise sobre emergência dos Estados, das classes e dos tipos de autoridade e dominação política. Weber parte do pressuposto de que a modernidade está alicerçada no direito racional-formal. Com isso, aponta a relevância política e institucional dos aspectos legais do governante para a formação do Estado, arrecadação de tributos, melhoria de receitas, submissão ao controle direto da população, etc.

Esse processo de formação do Estado, associado ao aparecimento e desenvolvimento do capitalismo e à expansão da razão governamental, teve como consequência a extinção da servidão e o aparecimento do trabalho livre. Este caráter livre impulsionou o direito subjetivo de celebrar contratos para empregar a força de trabalho, resultando desses fatores o surgimento do direito de propriedade e de contrato para o intercâmbio de bens e serviços. 
A expressão "burocracia" - consoante a teoria weberiana, qual seja, a burocratização da atividade governativa - traz em seu bojo o sentido de eficiência do aparato da estrutura estatal, haja vista a técnica de distribuir tarefas no processo de produção e gestão. O "parcelamento" de atribuições burocráticas contribuiria para que a máquina administrativa se orientasse pela eficácia de rotina, previsibilidade e eficiência administrativa.

Sob a ótica de Weber ${ }^{3}$, a ideia de burocracia rege-se pelo princípio das atribuições fixas que delimitam as esferas de competência, cuja caracterização opõe o agente superior ao seu subordinado. A distribuição dos deveres e o exercício dos direitos correspondentes refletem o cumprimento regular e contínuo deles de maneira hierárquica com funções delineadas e determinadas. Observa-se um alto controle dos subalternos pelas autoridades superiores.

A burocracia para Weber é uma estrutura conceitual ideal, tendo por fundamento, certos elementos empíricos, relacionados à impessoalidade, formalismo e profissionalização, que se agrupam, logicamente, em uma forma precisa e consistente (MOTTA, 1981). Segundo Weber, como decorrência de suas atribuições institucionais, no Estado Moderno é a burocracia quem efetivamente governa.

Trata-se de uma noção importante para compreender o desenvolvimento da burocracia no Brasil. Obviamente, não se trata de aplicar literalmente a teoria de Weber no país, especialmente porque aqui, ao lado de uma burocracia tecnicamente consolidada, esteve presente uma administração altamente patrimonialista e orientada por critérios não-técnicos.

\section{Brasil colonial}

No Brasil colonial, a estrutura governamental atingiu três ciclos históricos definidos a partir de seu descobrimento. O primeiro período inicia com a chegada de Cabral até a instalação do governo geral, em 1549. O segundo, por sua vez, começa com a instalação do governo geral (1549) até final do século XVIII. Por fim, o terceiro ciclo se iniciou no século XVIII e encerrou-se com a independência do país em 1822.

Durante o segundo ciclo, Felipe II, rei da Espanha, assumiu a Coroa de Portugal - por tornar-se possessão de Habsburgo - e demonstrou seu interesse pessoal pela expansão da burocracia e pelo aperfeiçoamento do sistema judicial do Império (SCHWARTZ, 2011). O ápice,

\footnotetext{
${ }^{3}$ Segundo Maurício Tragtenberg (2006), Weber admite a operacionalidade da burocracia, a impessoalidade, a objetividade adstrita a um expediente, seu recrutamento impessoal, a hierarquia fundada em diplomas credenciadores, o saber especializado, o cargo como profissão, a fidelidade ao cargo, a direção monocrática, garantindo formalmente rapidez, pontualidade, continuidade e eficiência no modus operandi burocrático
}

Revista de Direito da Cidade, vol. 07, no 4. Número Especial. ISSN 2317-7721 pp.1628-1644 1631 
segundo Schwartz, foi a criação do Tribunal Superior brasileiro, que representa um marco para a história administrativa e social da Colônia. Os magistrados deste tribunal eram denominados de "burocratas magistráticos", tornando-se a magistratura a "espinha dorsal do governo real". Seguindo a magistratura, vieram os tabeliães, amanuenses e inspetores portuários e tesoureiros. Cargos com menores requisitos técnicos eram concedidos frequentemente como dotes a viúvas e órfãos, intitulando-os de cargos na "burocracia não profissional".

No "Estado absolutista português" - como se nomeou à época da colonização na revisão e organização das leis durante o reinado de Afonso $\vee(1446)$ - não se vislumbrava uma nítida distinção entre a esfera pública, como campo de atividade do Estado, e a esfera privada, como campo de ação dos indivíduos.

Vale dizer que essa ausência de limitação das fronteiras entre o bem público e o privado não ocorreu de forma plena no reinado de Dom João IV (1640-1656). Este reinado se caracterizou por uma série de medidas administrativas, principalmente no âmbito fiscal, visando restringir os poderes do Rei em prol do "bem público", com o fito de delinear regras para empréstimos ou se apossar de bens privados para seu uso. Trata-se de algo que contradiz a teoria weberiana de burocracia como um espaço técnico de decisões administrativas.

A figura da administração colonial demonstrou uma situação sui generis no país. Ao tempo em que enfraquecia o rei, os administradores do Brasil tinham de improvisar medidas, já que as atividades executivas e judiciárias eram concentradas na mesma pessoa. Foram criados cargos como o de Governador-geral, além de órgãos administrativos militares, judiciários e fazendários. Mostra-se nítida a ideia da máquina burocrática nas Colônias que estão próximas da Metrópole, especialmente na sede do governo geral e das capitanias à sua volta. Nas demais regiões, foram impostas as ordens religiosas, especialmente a dos jesuítas - considerada um Estado dentro do Estado -, ou as regras dos grandes proprietários rurais. Isto também contradiz com a ideia de autoridade técnica da burocracia analisada por Weber.

A administração civil do Brasil colonial, sobretudo no século XVII, caracterizou-se pela delegação tripartite de poderes: político-militar, fiscal e judicial (Idem). Embora houvessem ramos distintos de governo, regulamentos e padrões próprios, eles reforçavam a ideia de um só centro de poder. Na pirâmide do poder, via-se, em primeiro lugar, a figura do governador-geral - chefe político de Estado - e do presidente do Tribunal Superior. Em seguida, estava presente o bispo, mais alta autoridade da instituição eclesiástica e responsável pelo bem-estar espiritual do povo da 
colônia, com deveres, funções e jurisdições sobrepostos em diversos ramos do governo. A relação com a religião permitia um sistema de controle recíproco, que não era livre de tensões.

Vale dizer que, ao tratar sobre a magistratura nacional, Schwartz assevera que foram os princípios da máquina burocrática local da época: antiguidade, mérito, precedência e nepotismo (Idem).

Neste sentido, durante o Brasil colonial, observa-se a construção de uma burocracia altamente permeável ao interesse particular e com dificuldades de se estabelecer a partir de decisões eminentemente técnicas. Isto reforçou o modo patrimonialista de administração das cidades brasileiras.

\section{Ação administrativa luso-brasileira pombalina}

No século XVIII, um feito histórico ocorre com a ascensão de Dom José I ao trono português (1750). O novo governante designou como Ministro o diplomata Sebastião José de Carvalho e Melo: o Marquês de Pombal. Pombal criou duas companhias privilegiadas de comércio a Companhia Geral do Comércio do Grão-Pará e Maranhão (1755) e a Companhia Geral de Pernambuco e Paraíba (1759).

Marques de Pombal foi marcante para a história da ação administrativa luso-brasileira (1750-1777), expondo restrições e críticas aos ingleses e seus métodos de dominação econômica, como ressalta Avellar (1983, p. 9). O seu principal objetivo foi de liberar o comércio português da regulação inglesa e desenvolver a indústria nacional.

Neste sentido, Pombal implementou medidas administrativas para coibir o contrabando de ouro e diamantes e melhorar a arrecadação de tributos. Em Minas Gerais, por exemplo, o imposto de capitação foi substituído pelo antigo quinto do ouro. Pombal ainda impôs o confisco de bens aos jesuítas em 1759.

Marques de Pombal foi mais além nessa empreitada administrativa de "laicização" da Administração. Isso porque implementou em seu programa educacional a indispensabilidade de reformar os estudos menores e maiores, o incremento do ensino profissionalizante (aulas de comércio e artilharia), assim como a libertação do negro no Reino e do índio no ultramar. Além disso, Pombal contribuiu para a institucionalização da capacidade civil do indígena, culminando não só com a erradicação da administração comunal jesuítica no Estado do Maranhão, mas também com a unicidade linguística do Brasil. 
No campo da infraestrutura, Pombal teve como lema "administrar é prever e prover" e adotou um paradoxal pragmatismo e editou leis segundo as circunstâncias. Sua administração fiscalista e unitária produziu uma torrencial legislação limitativa do crédito e da livre mercancia, tendo por mérito assegurar a organicidade e unidade à ação administrativa econômica, resultante assim no aumento de arrecadação.

Dentre as providências administrativas pombalinas, destacam-se: centralização administrativa das capitanias, nova organização do Estado com sua laicização ao substituir a administração missionária, fomento da pecuária, estímulo à migração europeia, outorga de predicamento de vila às aldeias, enfraquecimento do nobre como força individual em prol do fortalecimento da nobreza como instituição, quer impedindo as distinções entre fidalgos puros e impuros, ou promovendo normas para o casamento compulsório dos aristocratas.

Neste sentido, Pombal destacou-se no desenvolvimento de iniciativas para a construção de uma burocracia mais independente sob o ponto de vista decisório. Ao buscar laicizar a administração pública e desenvolver o direito administrativo e tributário, Pombal buscou meios de fomentar uma administração pública mais orientada por critérios técnicos de desenvolvimento nacional, que foi importante para as cidades.

\section{O incremento do aparelho burocrático nacional}

Caio Prado Júnior (2011) afirma que a legislação administrativa da Colônia se caracteriza por ser um amontoado desconexo com determinações particulares casuísticas. Prado Júnior sustenta que seriam poucas normas gerais de direito público fixando de forma completa e definitiva as atribuições, estrutura e competência da administração pública, exceto no regime fiscal, em que houve maior criatividade para aprimorar a arrecadação.

Em 1807, a família real embarcou de Portugal rumo ao Brasil. A máquina burocrática portuguesa se mudou para a Colônia, tais como ministros, conselheiros, juízes, funcionários do Tesouro, patentes do exército e da marinha, membros do alto clero, o tesouro real, arquivos do governo. Vale destacar que também vieram vários livros que deram surgimento à Biblioteca Nacional do Rio de Janeiro.

Deste modo, iniciou-se o incremento do aparelho burocrático nacional. Em 28 de janeiro de 1808, D. João VI decretou a abertura dos portos do Brasil às nações amigas. No mês de abril, revogou decretos que impediam instalação de manufaturas na Colônia, isentou tributos para 
importação de matérias-primas destinadas à indústria, ofereceu subsídios para as indústrias de lã, da seda e do ferro e encorajou a invenção e introdução de novas máquinas.

A figura da Administração Pública já despontava, no Brasil Colônia, como um feixe de atribuições relevante, especialmente a partir da integração com a Igreja. As atividades administrativas de assistência social (proteção ao idoso, ao carente, etc.) e de ensino, fizeram com que a participação da Igreja na administração pública fosse expressiva.

Cabia à Coroa perceber o dízimo. Este tributo eclesiástico destinava-se à manutenção do clero e ingerência monárquica sobre a Igreja era incontestável, a ponto de criar e prover bispados, construir Igrejas, delimitar jurisdições territoriais, autorizar o estabelecimento de ordens religiosas, conventos, etc. A autonomia e independência não constituíam plenas prerrogativas eclesiásticas. Em outras palavras, a Igreja se afigurou como uma verdadeira repartição pública, sendo o clero o seu funcionalismo.

Na visão de Prado Júnior (2011, p. 353), a forma brutal no processo de seleção de empregados, a cobrança acachapante de tributos, seriam exemplos de falta de organização, eficiência e presteza de funcionamento da administração pública. Observa-se a complexidade de órgãos, a confusão de funções e competência, a ausência de método e clareza na confecção de leis, a regulamentação esparsa, desencontrada e contraditória, o excesso de burocracia em órgãos centrais que se acumula funcionalismo inútil e numeroso, etc.

Em agosto de 1820, a revolução liberal inspirada nas ideias ilustradas se desenvolveu em Portugal. No Rio de Janeiro, manifestações populares e das tropas portuguesas forçaram o rei a reformular o ministério, a criar juntas onde não existiam e a traçar eleições indiretas para as Cortes. Politicamente encurralado, o rei retornou a Portugal em abril de 1821, dando impulso a uma nova medida: a independência do Brasil.

José Bonifácio de Andrada destacou-se neste período histórico da política brasileira. Ele defendeu ideias progressistas no campo social, como a gradativa extinção do tráfico de escravos e da escravidão, a reforma agrária e a livre entrada de imigrantes no país. A Lei de 24 de outubro de 1832, com certo pionerismo, consagrou os juros, sendo estes limitados pelo Estado ao percentual de $6 \%$ nas condenações em juízo.

Segundo Prado Júnior, "a Administração portuguesa sempre foi uma ineficiência dolorosa" (Idem, p. 1686). Para este autor, ela "estendeu ao Brasil sua organização e seu sistema, e não criou nada de original para a colônia" confirmando a "falta de originalidade da metrópole no organizar administrativamente a colônia, a incapacidade por ela demonstrada" (Idem, p. 6396). Esta 
perspectiva confronta-se com a perspectiva de Weber, para o qual a burocracia moderna "destacase por uma qualidade que torna seu caráter inescapável essencialmente mais definitivo do que o daquelas outras: a especialização e o treinamento racionais", tornando "o funcionário moderno, como convém à técnica racional da vida moderna, está cada vez mais sujeito, constante e inevitavelmente, a um treinamento específico e cada vez mais especializado" (WEBER, 2012, p. 540).

A diferença de significado da expressão "burocracia" empregada no Brasil e a descrita por Max Weber pode ser vista em inúmeras situações locais, a saber: a falta de organização, eficiência e presteza do funcionamento do setor administrativo; os processos brutais empregados, a exemplo da cobrança de tributos; a complexidade dos órgãos públicos; a confusão de funções e competência; o excesso de burocracia dos órgãos centrais em que se acumula um funcionalismo inútil e numeroso; a centralização administrativa que fez de Lisboa a cabeça pensante única em negócios passados a centenas de léguas de distância. Segundo Prado Júnior, "tudo isto não poderia resultar noutra coisa senão naquela monstruosa, emperrada e ineficiente máquina administrativa burocrática que é a administração colonial” (PRADO JUNIOR, 2011, p. 6978).

A Revolução de 1930 tentou implementar uma burocracia funcional mais próxima da perspectiva weberiana. A história brasileira decorrente do Estado Novo demonstrou uma excessiva centralização na máquina administrativa. Houve acordos de cooperação técnica e treinamentos de agentes públicos entre Brasil e Estados Unidos. Também foi criado o Conselho Federal do Serviço Público (CFSPC, em 1936) e, mais tarde, o Departamento Administrativo do Serviço Público (DASP, 1938).

A Era Vargas (1930-1945) e o regime militar (1964-1985) foram férteis na produção de leis e regulamentos. $\mathrm{O}$ excesso regulatório disposto nas leis e atos administrativos normativos reforça o controle exacerbado do governo sobre o andamento da máquina administrativa, que produziu reflexos no desenvolvimento das cidades.

Em 1961, a reforma urbana, dentre outras questões políticas e econômicas ${ }^{4}$, despontava como um grande desafio, tendo o povo clamado por reformas estruturais básicas. No decorrer do Governo de João Goulart, agravado por Jânio Quadros, a taxa de desemprego aumentou não só em decorrência da explosão populacional, mas também do crescimento econômico, resultando numa

\footnotetext{
${ }^{4}$ São exemplos de questões políticas e econômicas da época: relações com os Estados Unidos, renegociação da dívida externa, lei de remessa de lucros e dividendos, acordo para os investimentos norte-americanos, relações com países socialistas, reforma agrária, etc.
} 
vigorosa emigração das áreas rurais para as regiões urbanas. Como consequência deste movimento socioeconômico, o desequilíbrio urbano foi causado por entraves institucionais, tais como a precariedade no campo educacional, na pesquisa científica e tecnológica e na saúde pública. A presença do patrimonialismo na Administração Pública desde Brasil Colônia, especialmente a indicação política para os setores administrativos, permaneceu inalterada nas décadas de 60 e 70 e contribuiu para o imbróglio burocrático da gestão urbana.

O Presidente Dutra, por exemplo, fez votar na Câmara uma lei para superar a descontinuidade administrativa denominada de Plano SALTE (Saúde, Alimentação, Transporte, Educação).

Em 1986, no relatório denominado "Para um novo Pacto Social", Jaguaribe (JAGUARIBE et al, 1991, p. 35) sustentou a necessidade de se proceder uma substancial ampliação dos serviços sociais e um aperfeiçoamento do seu padrão de eficiência e qualidade. O autor apontou várias causas a se levar em consideração por ocorrer deficiência nos respectivos serviços, mas um fator chama atenção: ao mesmo tempo em que assevera ser o setor privado, através da privatização, a única forma do Estado prestar bons serviços à crescente demanda da população, teve o condão de desestimular sua efetiva aplicação pelo governo ao imputar o desaparelhamento deste às demandas da sociedade.

Sob esse prisma, surgiram demandas por estruturas governamentais mais eficientes. Os servidores seriam organizados conjuntamente e realizariam tarefas para alcançar externamente a população que depende de seus serviços públicos. Trata-se da figura de estruturalismo - prática comum nos anos 70 no Brasil -, em que o cidadão assume forma de estruturas dentro da estrutura organizacional (TONINI, 2012). Nesse contexto, o serviço público passa a introduzir o formalismo nos procedimentos internos, o que pode gerar desafios na efetivação de direitos, pois o caráter patrimonialista permaneceu.

Nessa realidade, observa-se que os procedimentos de gestão político-administrativa consolidaram uma visão patrimonialista, formalista, centralizadora e reguladora do Estado. Isto se conjuga a uma legislação jurídica complexa e numerosa. Ou seja, a capacidade operacional do Estado brasileiro, em termos de competência e de confiabilidade aos níveis e setores estratégicos da administração pública, requereu uma transformação no modelo de gestão urbana. 


\section{CIDADES E ADMINISTRAÇÃO PÚBLICA}

\section{Burocracia e cidades}

A cidade é um importante instrumento de alcance do bem-estar do cidadão. Sendo o homem o gestor do espaço urbano, o planejamento urbano se insere nesta compreensão por se tratar da atividade de planejar e de ser uma ação qualificada do Poder Público. Em função da articulação entre o formalismo e o patrimonialismo, a burocracia enfrenta diversos desafios no desenvolvimento das cidades e do planejamento urbano, tais como a relativa ineficiência na prestação de serviços públicos. Tais desafios também podem ser encontrados em diversos assuntos, tais como a prestação de políticas públicas, serviço público, fomento, mobilidade urbana, moradia, etc.

De fato, os instrumentos jurídicos e políticos e os mecanismos eficientes de humanização das cidades interferem na vida dos cidadãos. Vale lembrar que o Poder Público para a gestão das cidades, a exemplo do desenvolvimento de planos diretores de mobilidade urbana para cidades com população acima de 20 mil habitantes. Ou seja, o ponto específico do debate versa sobre o sentido do termo "burocracia" e sua implicação na implementação de políticas públicas urbanas. Versa, então, sobre quando e onde as práticas administrativas, bem como o ordenamento legal, influenciaram as funções principais das cidades: habitar, trabalhar, recrear e circular.

A retrospectiva ao Brasil colônia foi importante para compreender a expressão "burocracia" e seu processo de recrudescimento conceitual na realidade urbana. Com o desenvolvimento do país, a urbanização cresceu e as políticas urbanas - tais como moradia, transporte, saneamento básico, políticas de resíduos sólidos - impuseram ao Estado uma nova postura de ação mais formalista.

Neste sentido, a industrialização e desenvolvimento econômico das décadas 1940 e 1950 fizeram que o país sofresse influências internacionais por planejamento estruturado. Inclusive, a figura do planejamento foi incorporada ao Plano de Metas do governo de Juscelino Kubitschek e repetida no Plano Trienal de João Goulart, na década de 1960.

No Brasil, a partir do século XX, a situação nas cidades se agravou, principalmente devido à urbanização crescente. Em meados da década de 60, o movimento em prol da Reforma Urbana começou a se fortalecer (SILVA, 2008). No entanto, o golpe militar de 1964, ao limitar os direitos civis e políticos, inibiu a participação popular na questão urbana. 
O regime militar consolidou a forma de atuação planejada, mas manteve a característica patrimonial. A centralização governamental acentuou a divisão das instituições nacionais e impossibilitou a participação popular. Ocorre, desta feita, o fenômeno da "superestimação da capacidade de atuação do Estado" (SANT'ANNA, 2007, p. 151), ignorando as forças do mercado e os entraves institucionais no campo da própria máquina pública.

Com a promulgação da Constituição da República de 1988 (CRFB) foi fortalecido o modelo de Estado redistributivo, universalista e igualitário de organização social. No que concerne às cidades, ressurgiu a importância do planejamento urbano no âmbito do ordenamento jurídico. A Constituição de 1988 também consolidou a ideia de função social, tendo por objetivo ordenar o pleno desenvolvimento das funções sociais da cidade e garantir o bem-estar de seus habitantes. $\mathrm{O}$ Estado passou a ter que planejar de maneira mais eficiente e eficaz, especialmente porque surgiram instrumentos jurídicos importantes no Brasil, tais como as Leis n. 10.257/2001 (Estatuto da Cidade) e 12.587/2012 (Política Nacional de Mobilidade).

Atualmente, a fragilidade institucional e do planejamento das cidades, mesmo dos grandes centros urbanos, torna importante a adequada gestão e planejamento de políticas públicas para otimizar ao máximo os investimentos em infraestrutura. O deslocamento do cidadão para a cidade foi facilitado pelo veículo, o que refletiu na perda do padrão de sustentabilidade, que é um dos principais desafios atuais. O aumento de renda da população estimulou a "motorização do cidadão", o que proporcionou um agravamento na sustentabilidade ambiental e qualidade de vida urbana. Nos últimos anos, os governos têm praticado políticas de diminuição da carga tributária dos veículos, a facilitação ao acesso do crédito e a regulação do preço do combustível.

Tendo em vista os avanços e desafios da tensão entre o tecnicismo e o patrimonialismo, as cidades enfrentam a questão do planejamento urbano de maneira difusa. Isto tem gerado, em muitos casos, uma falta de planejamento de curto, médio e longo prazo nas cidades e, como consequência, o caos urbano.

\section{Caos urbano}

O cenário das cidades nos dias atuais é desafiador e envolve aspectos políticos, econômicos e sociológicos da formação da burocracia brasileira. Atualmente, tem sido associada a burocracia ao que se denomina como "caos urbano", especialmente por conta da tensão entre a formação patrimonial do Estado e a recente incorporação da tecnocracia. 
A procura por emprego e a melhor qualidade de vida fez as cidades terem um alto volume populacional, o que trouxe desafios expressos nos índices sociais e econômicos. Com frequência, a administração pública tem apresentado indicadores negativos do ponto de vista da eficiência e efetividade da prestação de serviços públicos. Para melhorar esses indicadores na cidade, torna-se importante aprimorar e agilizar a atividade estatal no sentido de aperfeiçoar o sistema de leis e torná-las mais efetivas. Isto demanda uma ação governamental com medidas que incrementem segurança jurídica à propriedade privada, agilização dos processos administrativos, garantias de cumprimentos de contratos, investimentos na infraestrutura que podem externalizar melhorias, por exemplo, na mobilidade urbana, no nível de emprego, na capacitação técnica e aumento da renda per capita da população.

Em regra, têm sido atribuídos como fatores burocráticos que influenciam no "caos urbano" os seguintes:

1. A complexa obtenção de licenciamento ambiental;

2. O atraso tecnológico do setor elétrico;

3. O acesso complexo à financiamento imobiliário;

4. A pouca acessibilidade aos benefícios financeiros dos bancos públicos, como a Caixa Econômica Federal e Banco do Brasil, que disponibilizam juros menores que os praticados no mercado;

5. A falta de estrutura dos cartórios para atender a uma demanda acima da média por regularização de escrituras/registros;

6. A lei licitatória, a estrutura judicial cartorária como força capaz de incidir nesse processo;

7. As funções constitucionais dos órgãos de controle administrativo e ambiental e suas atuações como fator de represamento à atividade administrativa;

8. A falta de capacitação técnica do servidor público;

9. A existência do estado regulador em atividades não exclusivas do Estado;

10. A falta de regulamentação de pontos cruciais previstos na Constituição da República (CRFB);

11. A irreversibilidade do sistema previdenciário (público para privado e vice-versa) como óbice da saída do servidor público do aparelho estatal é outro aspecto que deve ser levado em consideração;

12. O agente público pode ser responsabilizado pela "burocracia" brasileira, hoje apontada como sinônimo de paralisia administrativa pela sociedade em geral? 
Observe-se que, em alguma medida, tais fatores estão relacionados ao planejamento urbano e ao desenvolvimento da burocracia no país. A incidência de novas formas de atuar, as reivindicações populares e o contexto de caos urbano têm obrigado o Poder Público a buscar mecanismos mais dinâmicos e socialmente eficientes. Neste sentido, tem sido realizada uma nova forma de administração pública das cidades em consonância com uma mudança na própria concepção de atraso da burocracia ${ }^{5}$.

A este respeito, há de se entender o termo "uma nova forma de administração pública" sob a perspectiva de um processo de crescimento das cidades brasileiras que encontrou fundamento na recente história constitucional brasileira. A CRFB dispôs de um capítulo acerca da política urbana, que é regulamentado pelo Estatuto da Cidade (Lei no 10.257/2001). Na inspiração deste Estatuto, busca-se equilibrar os direitos individuais e as funções sociais da propriedade e da cidade, configurando-se uma "nova forma de administração pública". Neste sentido, foram criadas normas urbanísticas orientadas pela capacidade de ação e gestão dos municípios, com a implementação de políticas públicas adequadas acessíveis. Trata-se de uma forma participativa de conceber a administração municipal em assuntos estratégicos, tais como moradia, saneamento básico, infraestrutura urbana, transporte e serviços públicos.

\section{CONSIDERAÇÕES FINAIS}

A partir da década de 30 no Brasil, com o fortalecimento da indústria, ocorreu a transformação de uma economia agrária para uma industrializada, iniciando um movimento social em direção ao centro urbano e, consequentemente, a necessidade de se aprimorar a gestão pública. Isto porque o Poder Público passou a ter mais deveres de promoção de políticas públicas crescentes existentes nas cidades em prol de sua população urbana. Deu-se início a tentativa de profissionalização do funcionalismo com a criação do Departamento Administrativo do Serviço Público (DASP) em 1938.

As estruturas organizacionais não acompanharam o ritmo acelerado de crescimento das cidades brasileiras e o modelo gerencial da administração pública exibiu tendências de restrição à modernização do aparelho estatal. Mesmo assim, com a industrialização e a urbanização, foram editadas na década de 40 as garantias trabalhistas.

\footnotetext{
${ }^{5}$ São exemplos de autores que trabalham com esta ideia: CARVALHO (2009), CARVALHO FILHO (2013), DI PIETRO (2013), FIGUEIREDO (2008), GASPARINI (2012), JUSTEN FILHO (2012), MEIRELLES (2013), MELLO (2013) E MOREIRA NETO (2009).
} 
Em decorrência desses fatores, a taxa de crescimento urbano tornou-se maior que o percentual de industrialização, surgindo problemas de desemprego. Associe-se a isso o modelo burocrático de administração baseado no seguinte:

1. Caráter legal das normas e regulamentos;

2. Hierarquia funcional;

3. Imparcialidade nas relações;

4. Rotinas e procedimentos padronizados;

5. Competência administrativa. A submissão da Administração aos comandos legais (o agente público somente pode agir de acordo com a lei) não evitou o distanciamento do público.

A situação da burocracia brasileira chegou ao ponto do governo de Ernesto Geisel criar, em julho de 1979, o Ministério Extraordinário para a Desburocratização, sob o comando de Hélio Beltrão, cujo objetivo era trazer benefícios de integração ao cidadão comum através de medidas efetivas de acesso descomplicado aos canais da máquina governamental.

Indaga-se: a administração pública burocrática influiu e ainda influi como agente do caos urbano? Há diversas versões para a explicação deste fenômeno. A centralização do poder de legislar ou arbitrar sobre regras já existentes tende à formação de uma cúpula organizacional de decisões. No entanto, essa rigidez pode ter duas feições: os que decidem não possuem contato direto com os problemas e a camada social urbana que vivencia a problemática. Com isto, formamse camadas sociais estanques e economicamente distintas.

Por fim, falando em cidade - ente federativo mais próximo do cidadão -, a profusão de leis provoca reflexos na sua organização administrativa, posto que se constata: (a) o controle técnico do poder público é resultante do complexo sistema político constitucional brasileiro; (b) as normas legais impostas à comunidade criam etapas infindáveis que se percorre na Administração Pública para se atingir um objetivo que se quer alcançar; (c) as atividades desenvolvidas significam formas burocráticas que traduzem a vontade política do setor público de não implementar políticas públicas, como a educação, a saúde, o transporte público, a urbanização (moradia e saneamento) e o lazer.

Enfim, a ausência de participação e a aproximação dos serviços públicos da população, em contraste com o excesso de atribuições de prestação de serviços públicos a serem desempenhados, desembocam numa intricada atuação da gestão pública. 


\section{REFERÊNCIAS}

AVELLAR, Hélio da Alcantara. Administração pombalina. Brasília: UNB, 1983

CARVALHO, Raquel Melo Urbano de. Curso de Direito Administrativo. Salvador: Juspodium, 2009

CARVALHO FILHO, José dos Santos. Manual de Direito Administrativo. São Paulo: Atlas, 2013

DI PIETRO, Maria Sylvia Zanella. Direito Administrativo. São Paulo: Atlas, 2013

FIGUEIREDO, Lúcia Valle de. Curso de Direito Administrativo. São Paulo: Malheiros, 2008

GASPARINI, Diógenes. Direito Administrativo. São Paulo: Saraiva, 2012

JAGUARIBE, Helio et al. Brasil, Reforma ou Caos. São Paulo: Paz e Terra, 1991

JUSTEN FILHO, Marçal. Curso de Direito Administrativo. São Paulo: RT, 2012

MEIRELLES, Hely Lopes. Direito Administrativo Brasileiro. São Paulo: Malheiros, 2013

MELLO, Celso Antônio Bandeira de. Curso de Direito Administrativo. São Paulo: Malheiros, 2013

MOREIRA NETO, Diogo Figueiredo. Curso de Direito Administrativo. São Paulo: Forense, 2009

MOTTA, Fernando C. Prestes. Burocracia e autogestão: a proposta de Proudhon. Tese de doutoramento. São Paulo: EAE/SP-FGV, 1981

O'DONNELL, Guilhermo. Teoria Democrática e Política Comparada. Revista de Ciências Sociais, Rio de Janeiro, vol. 42, n. 4, 1999.

PRADO JUNIOR, Caio. Formação do Brasil Contemporâneo - Colônia. São Paulo: Companhia das Letras, 2011

SANT'ANNA, Mariana Senna. Planejamento urbano e qualidade de vida - Da Constituição Federal ao plano diretor. In: DALLARI, Adilson Abreu e DI SARNO, Daniela Campos Libório (Coordenadores). Direito urbanístico e ambiental. Belo Horizonte: Fórum, 2007.

SILVA, Renata Gomes da. Aspectos das limitações ao direito à moradia. Revista da Faculdade de Direito da Universidade de São Paulo, São Paulo, vol. 103, 2008

SCHWARTZ, Stuart. Burocracia e Sociedade no Brasil Colonia. O Tribunal Superior da Bahia e seus desembargadores, 1609-1751. São Paulo: Companhia das Letras, 2011

TRAGTENBERG, Maurício. Burocracia e ideologia. São Paulo: UNESP. 2006

TONINI, Creusa da Penha. Disfunções burocráticas em uma estrutura organizacional pública. Dissertação de mestrado. Vitória: FUCAPE, 2012 
WEBER, Max. Economia e Sociedade - Fundamentos da Sociologia Compreensiva. Brasília: UNB, 2012

Trabalho enviado em 02 de agosto de 2015.

Aceito em 18 de outubro de 2015. 